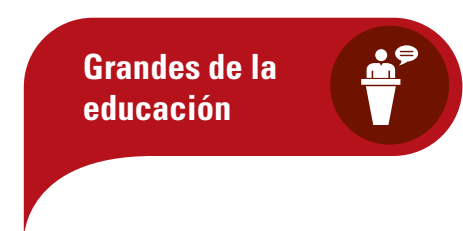

\section{Lorenzo Millani}

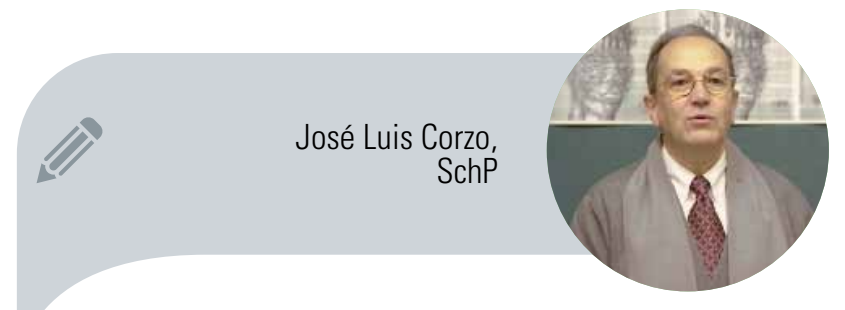

Universidad Pontificia de Salamanca grupomilani@movistar.es

\section{El papa Francisco ha citado al maestro y cura de Barbiana}

Fue el pasado 10 de mayo de 2014 ante una concentración muy numerosa en la plaza de San Pedro. Era la primera vez que lo hacía un papa, y ante la escuela (pública y privada) de toda Italia:

\begin{abstract}
"La escuela nos enseña a entender la realidad. Ir a la escuela significa abrir la mente y el corazón a la realidad, en la riqueza de sus aspectos, de sus dimensiones. ¡Y esto es bellísimo! \{...\} Si uno ha aprendido a aprender -y este es el secreto, ¿eh?, japrender a aprender!- esto le queda para siempre, permanece una persona jabierta a la realidad! Esto lo enseñaba también un gran educador italiano, que era un sacerdote: don Lorenzo Milani"1.
\end{abstract}

Este cura tan joven, fallecido con 44 años hace menos de 50 no fue muy bien visto por su Iglesia. En España, por ejemplo, el silencio de Escuelas Católicas (antes FERE) sobre él es atronador. Y, sin embargo, sólo al español se ha traducido su libro Experiencias Pastorales², cuya venta y traducción fueron prohibidas por el Santo Oficio en 1958, cuando salió. A raíz de esa cita del papa aquella prohibición se declaraba superada. Pero don Milani no es ningún desconocido ni siquiera aquí. Al contrario. En 1975, en un pliego "primer premio" de la revista Vida Nueva ${ }^{3}$, a propósito del libro de sus alumnos Carta a una maestra, escribí: "Desde hace años corre por España un librillo que en cualquier tertulia pedagógica alguien ha leído... Es un alegato terrible, escrito por los chicos de una escuela de aldea, en la montaña toscana, a unos

1 Cf. el monográfico "El Papa rescata a Milani": Educar(NOS) 66 (2014) 4-5

2 L. MILANI, Experiencias pastorales (BAC, Madrid 2003) en adelante EP; en 1975 apareció también como Maestro y cura de Barbiana. Experiencias pastorales (Marsiega, Madrid). Traducción mía en ambos casos.

3 J.L. Conzo, "Dar la palabra a los pobres. Don Milani": Vida Nueva 973 (1975) 420-427; en adelante VN.
50 kilómetros de Florencia. Va dirigido a "la maestra", pero aun sin serlo resulta difícil evitar el sonrojo al leer.

\begin{abstract}
“De los licenciados universitarios italianos, son hijos de papá el 91,9\%; hijos de trabajador por cuenta ajena el 8,1 \% (Annuario Statistico Italiano 1963, tab. 113-4) \{...\}.

Vosotros decís que habéis suspendido solamente a los tontos y a los vagos. Sostenéis entonces que Dios hace nacer a los tontos y a los vagos en las casas de los pobres. Pero Dios no hace esos desaires a los pobres. Es más probable que seáis vosotros quienes se los hacéis... La más furibunda de las maestras protestó diciendo que nunca había tenido noticias de las familias de los muchachos: «Si un ejercicio merece un cuatro, yo le doy un cuatro ". La pobre no entendía que precisamente se le acusaba de eso. Porque no hay nada más injusto que tratar con igualdad a quienes son desiguales $\{\ldots\}$.

Vuestro horario es indecente. Un obrero trabaja 2.150 horas al año. Vuestros colegas funcionarios del Estado 1.630. Vosotros, desde un máximo de 738 (los maestros) a un mínimo de 468 (los profesores de matemáticas y de lengua extranjera) $\{\ldots\}$. 740 horas son dos horas al día. Y el chico tiene los ojos abiertos otras 14 horas diarias. En las familias privilegiadas son 14 horas de asistencia cultural de todo género. Para los campesinos son 14 horas de soledad y de silencio para ser cada vez más tímidos. Para los hijos de los obreros son 14 horas en la escuela de la persuasión oculta (nota: la publicidad se llama "persuasión oculta" cuando convence a los pobres de que cosas que no son necesarias son necesarias). Con el horario que tenéis, la escuela es una guerra contra los pobres. Si el Estado no puede imponeros un aumento de horario, no puede hacer escuela $\{\ldots\}$.

Ciertos colegios de curas son más honestos. Son instrumento de la lucha de clase y no lo disimulan. En los Barnabitas de Florencia, la mensualidad de un medio-pensionista es de 40.000 liras. En los Escolapios de 36.000 [en 1967]. Mañana y tarde están al servicio de un solo amo. No sirven a dos señores, como vosotros $\{\ldots\}^{\prime \prime 4}$.
\end{abstract}

El libro hizo furor en Italia un año antes de la revolución parisina de mayo del 68 ly está traducido a muchísimos idiomas no sólo europeos). La escuela quedaba al descubierto. AqueIlos muchachos desenmascaraban su clasismo, su servidumbre respecto de una clase sola. Lo cantaban las estadísticas, ofrecidas por los pequeños aldeanos con un desparpajo sorprendente" (VN).

\section{Con tanta difusión, ¿cómo explicar tanta ausencia en nuestras facultades de educación y no sólo en la escuela católica?}

"Para comprender la acogida, desprecio o rechazo, que Barbiana despierta en la pedagogía oficial y en la masa del profesorado, veterano o nuevo, que llega a conocerla, hay que percibir desde el principio que su aportación fundamental es una verda-

4 Escuela de Barbiana, Carta a una maestra (Barcelona 1970). Conocemos en

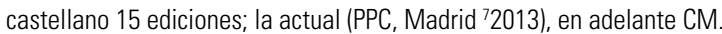




\section{Experiencias pastorales}

Con frecuencia me preguntan los amigos cómo hago para llevar la escuela y cómo hago para tenerla llena. Insisten para que les escriba un método, que les precise los programas, las materias, la técnica didáctica.

Equivocan la pregunta. No deberían preocuparse de cómo hay que hacer para dar escuela; sino sólo de cómo hay que ser para poder darla. Hay que ser. No se puede explicar en dos palabras cómo hay que ser, pero acabad de leer todo este libro y, tal vez, luego comprenderéis cómo hay que ser para hacer una escuela popular.

Hay que tener las ideas claras respecto a los problemas sociales y políticos. No hay que ser interclasista, sino que es preciso tomar partido. Hay que arder del ansia de elevar al pobre a un nivel superior. No digo ya a un nivel igual al de la actual clase dirigente. Sino superior: más de hombre, más espiritual, más cristiano, más todo.

Ya veréis cómo vienen los obreros, cómo dejan plantadas todas las diversiones del mundo y se echan en manos del cura para dejarse construir por él. De un cura así están dispuestos a aceptarlo todo: divisiones de tres cifras, verbos, dictado, historia, política, teología, broncas, malhumor. Todas las materias son buenas y todos los modos de explicarlas son buenos.

Lorenzo Milani. Experiencias pastorales. Madrid: B.A.C.

dera alternativa: la escuela básica no sólo ha de ser compensatoria (doposcuola) para repescar a los últimos, sino una verdadera contraescuela ${ }^{5}$. Pero muy pocos perciben a la primera que en la Carta el éxito escolar no es ventaja, sino la peor de las trampas:

\begin{abstract}
"Una escuela que selecciona destruye la cultura. A los pobres les quita el medio de expresión. A los ricos les quita el conocimiento de las cosas.

Gianni es un desgraciado porque no sabe expresarse; afortunado él que pertenece al gran mundo. Hermano de toda África, Asia y América Latina. Conocedor desde dentro de las necesidades de la mayoría. Pierino es afortunado porque sabe hablar. Desgraciado porque habla demasiado. Él, que no tiene nada importante que decir, que sólo repite cosas leídas en los libros, escritas por otro como él \{...\}" (CM, 107).
\end{abstract}

Un jaque mate a la escuela oficial no agrada en absoluto a quien sólo busca refuerzos y mejoras para ella. Ni siquiera recuerdan que nuestra escuela ya nació selectiva: era sólo para la burguesía y, después, se fue abriendo a todos. Así que, sin un neto análisis crítico "de clase", Barbiana no puede entusiasmar. Lo normal es que, como mucho, se comprenda en dos mitades: como algo asistencial, un refuerzo muy deseable contra el fracaso escolar y (ya menos) como alternativa radical a la escuela obligatoria"6.

Esté atento (y animoso) el benévolo lector. Los repertorios de pedagogos y escuelas suelen servirnos para retoques, mejoras y sugerencias. No para cuestionar el cuadro entero y denunciarnos. Ha sucedido también con Paulo Freire, otro cristiano que, a mi modesto entender, es el más grande pedagogo del siglo XX, muy poco seguido en nuestra escuela y en nuestra Iglesia. El obstáculo no suele ser ideológico, sino concreto: ¿qué chicos y situaciones tenemos delante? Freire, una masa analfabeta de Brasil;

5 De hecho, el folleto Scuola popolare di S. Donato, Doposcuola di classe. L'esperienza di Calenzano (Centro di Documentazione, Pistoia 1971) lo tradujo J. Gómez y Fernández Cabrera como Contraescuela. Por una escuela popular (Zero Zyx, Madrid 1973).

6 J.L. Conzo, La pedagogía de Milani en España e Iberoamérica. Ponencia en las VI Conversaciones pedagógicas de Salamanca: "Influencias italianas en la educación española e iberoamericana", Universidad de Salamanca 6 de junio 2014 (en prensa); en adelante El.

\section{Los repertorios de pedagogos y}

\section{escuelas suelen servirnos para retoques, mejoras y sugerencias. No para cuestionar el cuadro entero y denunciarnos}

Milani, campesinos emigrados a la industria o en una aldea de montaña que apenas aparece en los mapas. Y, en cambio, son una realidad universal, que le hizo hablar a Ernesto Balducci, el primero de todos, de "las Barbianas del mundo"7.

Acaba de cumplir 90 años una profesora de Secundaria, estrecha colaboradora de Milani, a cuya amistad y presencia en nuestra Casa-escuela Santiago Uno de Salamanca (1977-78) debemos muchas $\operatorname{cosas}^{8} y$, hace un par de meses, me sorprendió de nuevo: "don Milani (me dijo) no es una propuesta, sino una respuesta". En efecto, sin tener cerca los pobres concretos y los mecanismos que los hacen fracasar en nuestra escuela, es ridículo aplicar sus métodos a los niños y niñas bien de nuestros colegios. Puede que por eso dijera don Milani sobre los fundadores: "La mayor infidelidad con un muerto es serle fiel"; si siguiera vivo, aún cambiaría sus respuestas. Los pedagogos que escriben libros y dictan conferencias deben decirnos siempre en quién están pensando; que no sea sólo en este mundo desarrollado. El de los excluidos es mayor y también depende de nosotros.

7 "Di fronte al nostro mondo occidentale, le Barbiane del mondo..., perchè Barbiana è un nome emblematico, Barbiana non è più in Mugello: Barbiana è in Africa, è nel Medio Oriente, Barbiana è una comunità musulmana, Barbiana è nell'America latina. Le barbiane del mondo dicono che noi ci comportiamo come se il mondo fossimo noi", E. Balducci, "I nuovi ragazzi di Barbiana": L'Unità 26.6.1992; cf. Id., "Los nuevos chicos de Barbiana": Iglesia Viva 164/165 (1993) 229-237

8 Su reciente y único libro ha sido un best seller en Italia: Adele Corradi, Non so se don Milani (Feltrinelli, Milano 2012). Cf. el monográfico con amplias traducciones: “Dentro de Barbiana": Educar(NOS)57-58 (2012). 


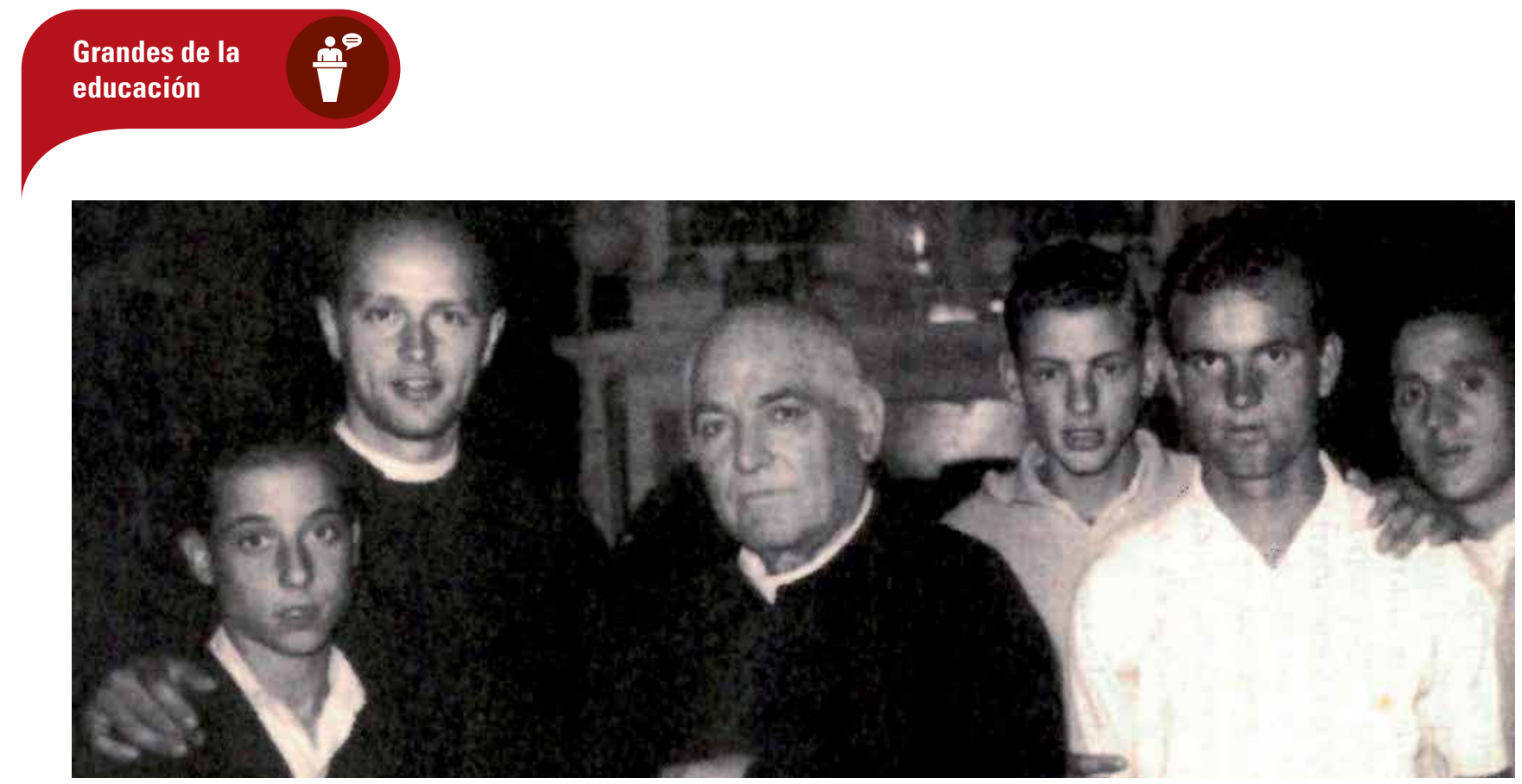

\section{Un retrato robot de Lorenzo Milani (1923-1967) ${ }^{9}$}

(1) Milani fue un joven estudiante de pintura; (2) de ascendencia familiar judía no practicante y alto-burguesa; (3) se convirtió a la fe cristiana a los 20 años en plena guerra (1943); (4), seminarista de inmediato, fue ordenado sacerdote en 1947; (5) en una parroquia semi-rural e industrial de Calenzano (Florencia) creó una escuela vespertina para jóvenes comunistas y democristianos; (6) tras siete años fue nombrado párroco (priore) de Barbiana, en un "monte perdido" y en suma pobreza; (7) allí hizo escuela a tiempo pleno a las niñas y niños del contorno, hasta su muerte.

\section{Los rasgos más salientes de su pedagogía}

(1) A aquellos campesinos, obreros y montañeses sólo les hacía falta la Palabra, no nuestra visión del mundo; (2) la escuela obligatoria no puede ser selectiva: el último era el preferido y se ayudaban unos a otros; (3) la escuela a "tiempo pleno" permite a diario leer y discutir en común el periódico; (4) escribir colectivamente (como la Carta a una maestra); (5) interrogar a los huéspedes; (6) salir de casa y viajar al extranjero para conocer otros ambientes y aprender otras lenguas; (7) todo para ayudar a los descartados y no convertir la escuela en "una cloaca de propaganda empresarial".

Pero el riesgo de tan escasos rasgos es desplazar la escuela de Barbiana fuera del sistema escolar obligatorio la la "educación no-formal", como dicen algunos casi con desprecio). Así la encasillan como una "experiencia" más o menos exótica de actividades didácticas laterales e ingeniosas. Era una escuela seria, pero no nació

\footnotetext{
"para enseñar, sino sólo para dar a los pobres los medios técnicos necesarios (esto es, la lengua) con que puedan enseñarnos las inagotables riquezas de equilibrio, sabiduría, concreción, religiosidad en potencia, que Dios ha escondido en su corazón $\{\ldots\}^{\prime \prime 10}$

"Quien cree en la vocación histórica de los pobres para llegar a ser clase dirigente (sin perder la propia personalidad y los propios dones) querrá
}

9 La primera biografía, también en Italia,

10 L. Milani a G. Meucci 2.3.1955 en Lettere di don L. Milani priore di Barbiana (a cura di M. Gesualdi) (Mondadori, Milano 1970) 34. ofrecerles una cultura entitativamente diversa de la que usa. 0 mejor aún, no querrá ofrecerles ninguna cultura, sino sólo el material técnico (lingüístico, léxico y lógico) necesario para fabricarse una cultura nueva que no tenga nada que ver con la otra" (EP 144).

\section{Las raíces cristianas de don Milani son muy profundas}

Algunos no las ven, porque él era un apasionado del carácter sobrenatural de muchos conceptos humanos que no necesitan la firma "del Amo"; la Palabra de Dios no lo es por sumarse a las nuestras, sino por encarnarse en ellas. Eso (y el no dividir más a sus parroquianos) hizo a su escuela aconfesional; (hasta en España hay más católicos en la escuela pública que en la privada). Además, "Ios curas han pedido el reconocimiento y dan notas y títulos como vosotros. También ellos proponen a los chicos el Dios-Dinero" (CM 96).

Milani huía del paternalismo. Sobre las becas para los pobres con buenas notas decía:

\footnotetext{
“Nadie que sienta preocupación por el progreso técnico tendrá nada que objetar: el progreso técnico exige especialistas y exige que estén bien dotados de cualidades para que el dinero público se gaste de la forma más eficaz.

Y esa es la palabra que para nosotros los cristianos estropea todo el proyecto y descubre su intención terrena e irreligiosa.

Se busca la eficacia antes que la justicia. El progreso de la técnica y el bienestar de todos, antes de haber asegurado a cada uno la dignidad humana $\{\ldots\}$

Estas cosas que las hagan los nazis, los soviéticos, los americanos, todos los que viven para la eficacia y que ponen en la eficacia la única razón de la vida. Pero no nosotros, que tenemos por única razón de la vida el contentar al Señor y demostrarle que hemos comprendido que cada alma es un universo de dignidad infinita $\{. .\}$.$" (EP 156).$
}

\section{Quizá lo esencial...}

La verdadera materia escolar de Barbiana era la vida, pasada por la caja de resonancia de aquellas conciencias del pueblo que habían escrito en la pared de la clase: I care (me importa, va conmigo). Todo. "La escuela, escribió Milani, se sienta entre el pasado y el futuro; es el arte delicado de conducir a los chicos por 
Lorenzo Milani "depende de un descubrimiento [...], un mundo que agoniza y otro que nace; una humanidad sulilmente dividida en dos, en cuyo seno hay que tomar partido cada día: a favor o en contra de los marginados

el filo de una navaja: por una parte crear en ellos el sentido de la legalidad, por otro, la voluntad de obtener leyes mejores". Estas palabras de su autodefensa ante los jueces, acusado coyunturalmente de haber defendido el entonces delito de la objeción de conciencia antimilitar, resumen bien su actitud y la enorme talla moral de su pedagogía:

\footnotetext{
"Un delito como el de Hiroshima requirió algún millar de corresponsables directos: políticos, científicos, técnicos, obreros, aviadores $\{\ldots\}$. Cada uno de ellos ha silenciado su propia conciencia fingiéndose a sí mismo que aquella cifra iba al denominador. Un remordimiento reducido a milésimas no quita el sueño al hombre de hoy $\{\ldots\}$.

De hacer caso a los teóricos de la obediencia y a ciertos tribunales alemanes, del asesinato de seis millones de judíos responderá sólo Hitler. Pero Hitler era irresponsable por loco; así que aquel delito no ha sucedido nunca porque no tiene autor. ¡Sólo hay una forma de salir de este macabro juego de palabras! Tener el coraje de decir a los jóvenes que todos ellos son soberanos, para quienes la obediencia ya no es una virtud sino la más sutil de las tentaciones; que no crean poder hacerse con ella un escudo, ni ante Dios ni ante los hombres; que es preciso que cada uno se sienta el único responsable de todo"11.
}

Y es que Lorenzo Milani "depende de un descubrimiento $\{\ldots\}$, un mundo que agoniza y otro que nace; una humanidad sutilmente dividida en dos, en cuyo seno hay que tomar partido cada día: a favor o en contra de los marginados. Hoy día, este dato comienza a sernos familiar, casi congénito $\{\ldots\}$, pero nuestro gran problema es despojarnos de nuestra mentalidad $\{\ldots\}$ y de los muchos intereses reales que ésta defiende. Por eso, ta vez, no cambiemos de forma de pensar mientras nuestra situación no varíe" (VN 422).

\section{Recursos didácticos}

Todos los posibles en un ambiente de montaña, sin luz ni teléfono ni agua corriente, donde la alternativa a la escuela era el establo y la azada. Era esencial el tiempo pleno (365 días al año) y la ayuda habitual de unos a otros; genial, la única

11 L. Milani, Carta a los jueces 18.10.1965 en Dar la palabra a los pobres. Cartas de L. Milani (ACC, Madrid 1995) 91-110, p.103

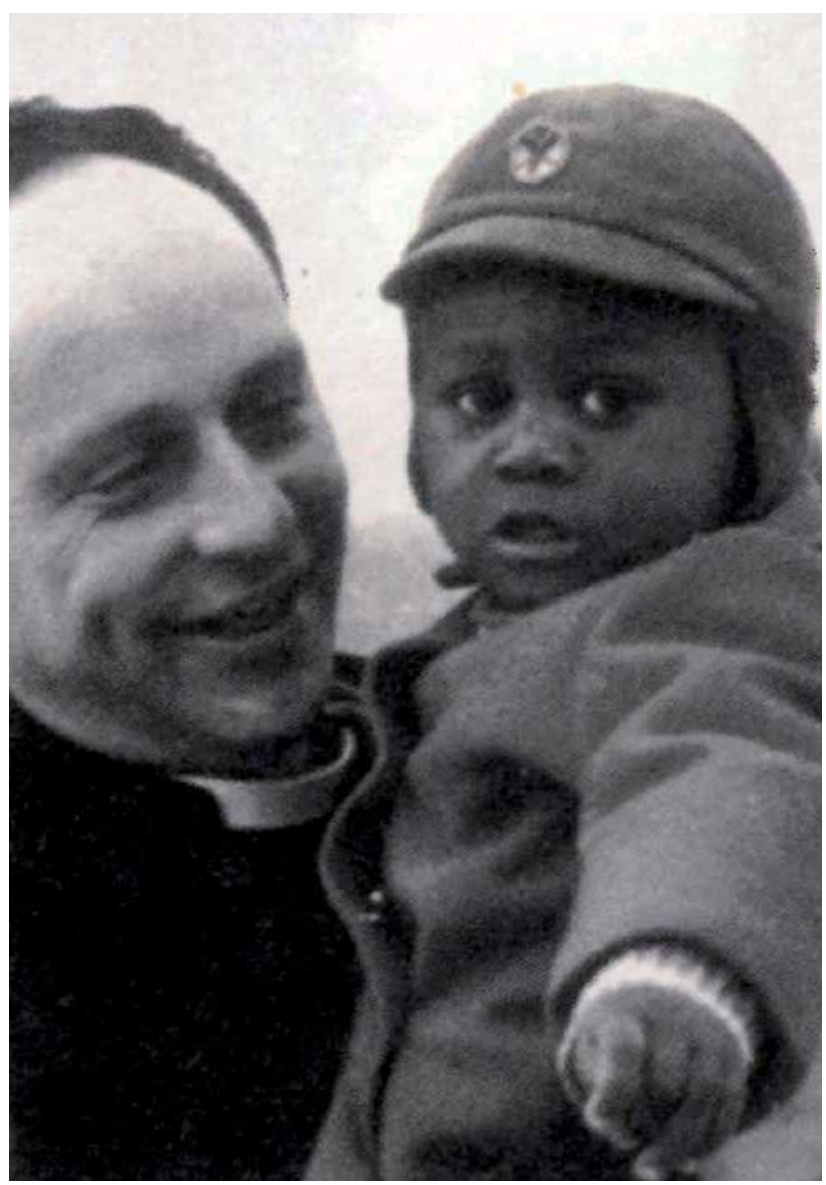

motivación escolar: ayudar a los descartados por el sistema y, para ello, aprender a comunicar, entender a todos y saber explicarse ante cualquiera. Además, iban lejos al cine y al teatro, se fabricaron instrumentos de astronomía, caballetes de pintor, partituras extensibles, y viajes solos al extranjero. Invitaban a huéspedes que se dejaran preguntar y discutían el periódico leído cada día en común. Milani recomendaba mucho la escritura colectiva como un hallazgo formidable capaz de parir el nosotros, en vez del yo ${ }^{12}$

La simple lectura de Carta a una maestra propició en Salamanca en 1971 una Casa-escuela, aún floreciente, internado abierto, y otras estructuras escolares como el doposcuola 0 apoyo postescolar y un centro Milani de FP agraria. Desde 1982 existe un movimiento de renovación pedagógica que imparte cursillos y edita la revista Educar(NOS). Información en: www.amigosmilani.es

12 En castellano hay varias huellas de estos recursos didácticos: un libro colectivo: Casa-escuela Santiago 1 de Salamanca, Escritos colectivos de muchachos del pueblo, (Popular, Madrid 1979, ${ }^{3} 1982$; hoy en ACC, Salamanca $\left.{ }^{4} 1996\right)$, con ilustraciones de J. L. Cortés. Cf. también, J.L. Corzo, La escritura colectiva. Teoría y práctica de la escuela de Barbiana, (Anaya, Madrid 1983). Objeto de múltiples cursillos: J.L. Corzo, Leer periódicos en clase (Popular, Madrid 1987, ${ }^{31992)}$. Cf. también Id., Educar es otra cosa. Manual alternativo entre Calasanz, Freire y Milani (Ed. Popular, Madrid 2007) y Educarnos con la actualidad. No viene en el libro pero entra en el examen (PPC, Madrid 2000). 

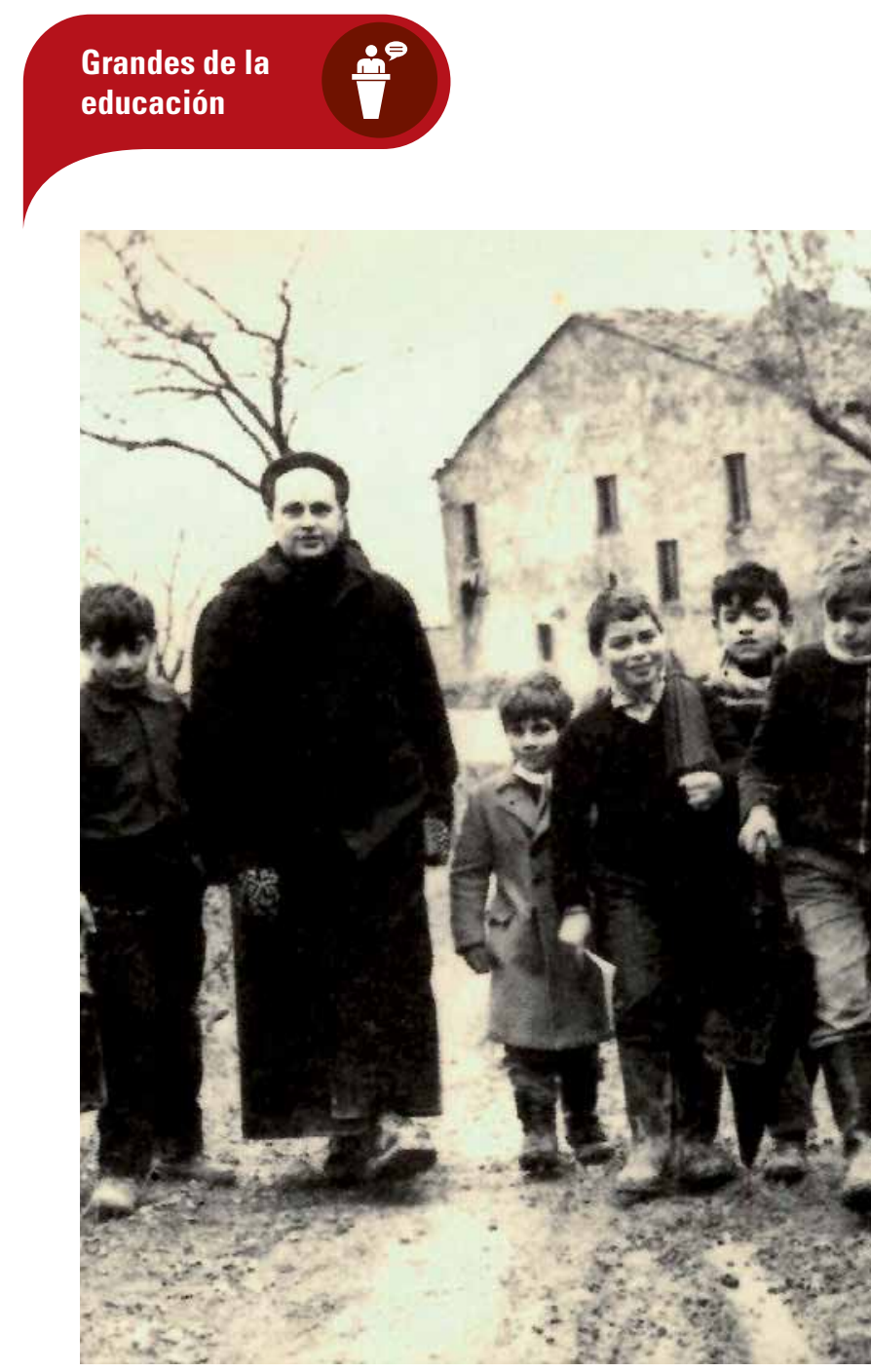

\section{Su lugar entre las tendencias pedagógicas contemporáneas}

"La revista española Cuadernos de Pedagogía incluyó a Milani en el año 2000 en su selección de sólo once pedagogos del siglo XX, pero renunció a clasificarlos. La lista es interesante, dado además el prestigio de la revista catalana en todo el mundo hispanohablante: María Montessori, F. Ferrer y Guardia, John Dewey, F. Giner de los Ríos, Celestin Freinet, A.S. Neill, A.S. Makarenko, Jean Piaget, Lorenzo Milani, Paulo Freire y L. Stenhouse. La revista (onsciente además de que "hoy en día se aprecia una obsesión, deliberada o inconsciente, por borrar el pasado colectivo, por desterrar de los discursos educativos actuales los referentes y las raíces $\{\ldots\}^{\prime \prime 13}$ ) dio explicaciones sobre su propia selección y citó los autores que "saltaron del listado definitivo", aunque pueden ayudarnos a formar nuestro propio mapa pedagógico contemporáneo: "Ferrière y la Escuela Nueva; Decroly y la globalización; Lobrot y la pedagogía institucional; Rogers y la pedagogía no directiva; Steiner y la pedagogía Waldorf; Bruner y la psicología cognitiva; Krishnamurti y el orientalismo; Holt y la desescolarización; Mendel y la pedagogía psicoanalítica; Sensat y la escuela pública y activa; Piussi y la diferencia sexual" (EI).

Situar a Milani depende de los criterios de clasificación. Él apenas cita autor alguno. No era un estudioso de pedagogía. Pero

13 J. Carbonell, "Prólogo. La memoria, arma de futuro"; y añade: "mucho se ha discutido sobre el poder del Estado y de sus administraciones educativas para integrar, devaluar, tecnificar y vaciar de contenido las pedagogías innovadoras", Pedagogías del siglo XX(Ciss Praxis, Barcelona 2000) 7.

\section{No era un estudioso de pedagogía.}

\author{
Pero podemos aportar alguna
}

\author{
observación: por ejemplo, la gran
}

sintonía con Paulo Freire

podemos aportar alguna observación: por ejemplo, la gran sintonía con Paulo Freire (1921-1997), aunque no se leyeran en vida de ambos $^{14}$. "Hay alguna sintonía explícita, incluso biográfica, con Mario Lodi (1922-2014), el maestro de Piadena, considerado el Celestin Freinet italiano, dentro de la escuela cooperativa, activa, popular y hasta socialista, en línea con la mejor renovación pedagógica italiana del siglo XX, con María Montessori (1870-1952) a la cabeza. Implícitos también hay acordes en su concepción de lenguaje con el más radical y marxista Antonio Gramsci (18911937). En cambio, no me consta por ahora relación o comentario recíproco alguno entre don Milani y otros comunistas contemporáneos suyos, como Gianni Rodari (1920-1980) o el también pedagogo italiano Bruno Ciari (1923-1970), discípulo de Codignola (1885-1965), en el Magisterio de Florencia.

Sería más difícil armonizar a don Milani con otro coetáneo suyo, Ivan Illich (1926-2002), a pesar de algunas coincidencias en la denuncia del sistema escolar. Don Milani es un apasionado defensor de la escuela y no quiere desescolarizar la sociedad". (EI).

En cualquier caso, la mejor presentación de don Milani son sus propios escritos leídos a la luz que hoy nos traen de África los inmigrantes.

14 P. Freire conoció después al de Barbiana y tengo el honor de que haya prologado nuestro libro Don Milani nella scrittura collettiva (en colaboración con F. Gesualdi exalumno de Barbiana: Gruppo Abele, Torino 1992).

\section{(4.) Dara SABEr más}

L. MILANı, Experiencias pastorales. Madrid: BAC.

Escuela de Barbiana, Carta a una maestra (PPC, Madrid '2013),

Dar la palabra a los pobres. Cartas de L. Milani. Madrid: Acción Cultural Cristiana

[Del exalumno de Barbiana Francesco Gesualdi]: Centro Nuevo Modelo de Desarrollo, Norte-Sur, la fábrica de la pobreza (Popular, Madrid 1997); y Geografía del Supermercado mundial (Setem, Pamplona 1998).

Textos y revista Educar(NOS). www.amigosmilani.es 